Printed

May 27, 1974
RFP-2170

UC-4 - CHEMISTRY

TID-4500-R-60

\title{
THE HEAT OF FORMATION OF PLUTONIUM HYDRIDE
}

\author{
Franklin L. Oetting
}

David R. Horrell

Research and Ecology

PRODUCT AND HEALTH PHYSICS RESEARCH

This report was prepared as an account of work
sponsored by the United States Government. Neither
the United States nor the United States Atomic Energy
Commission, nor any of their employees, nor any of
their contractors, subcontractors, or their employees,
makes any warranty, express or implied, or assumes any
legal liability or responsibility for the accuracy, com-
pleteness or usefulness of any information, apparatus,
product or process disclosed, or represents that its use
would not infringe privately owned rights.

DOW CHEMICAL U.S.A.

ROCKY FLATS DIVISION

P. O. BOX 888

GOLDEN, COLORADO 80401

Prepared under Contract AT(29-1)-1106

for the

Albuquerque Operations Office

U. S. Atomic Energy Commission

SUBJECT DESCRIPTORS

Heat of solution

Heat of formation

Plutonium

Plutonium hydride

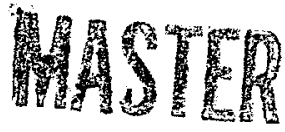




\section{DISCLAIMER}

This report was prepared as an account of work sponsored by an agency of the United States Government. Neither the United States Government nor any agency Thereof, nor any of their employees, makes any warranty, express or implied, or assumes any legal liability or responsibility for the accuracy, completeness, or usefulness of any information, apparatus, product, or process disclosed, or represents that its use would not infringe privately owned rights. Reference herein to any specific commercial product, process, or service by trade name, trademark, manufacturer, or otherwise does not necessarily constitute or imply its endorsement, recommendation, or favoring by the United States Government or any agency thereof. The views and opinions of authors expressed herein do not necessarily state or reflect those of the United States Government or any agency thereof. 


\section{DISCLAIMER}

Portions of this document may be illegible in electronic image products. Images are produced from the best available original document. 
RFP-2170

$\circ$ 


\section{CONTENTS}

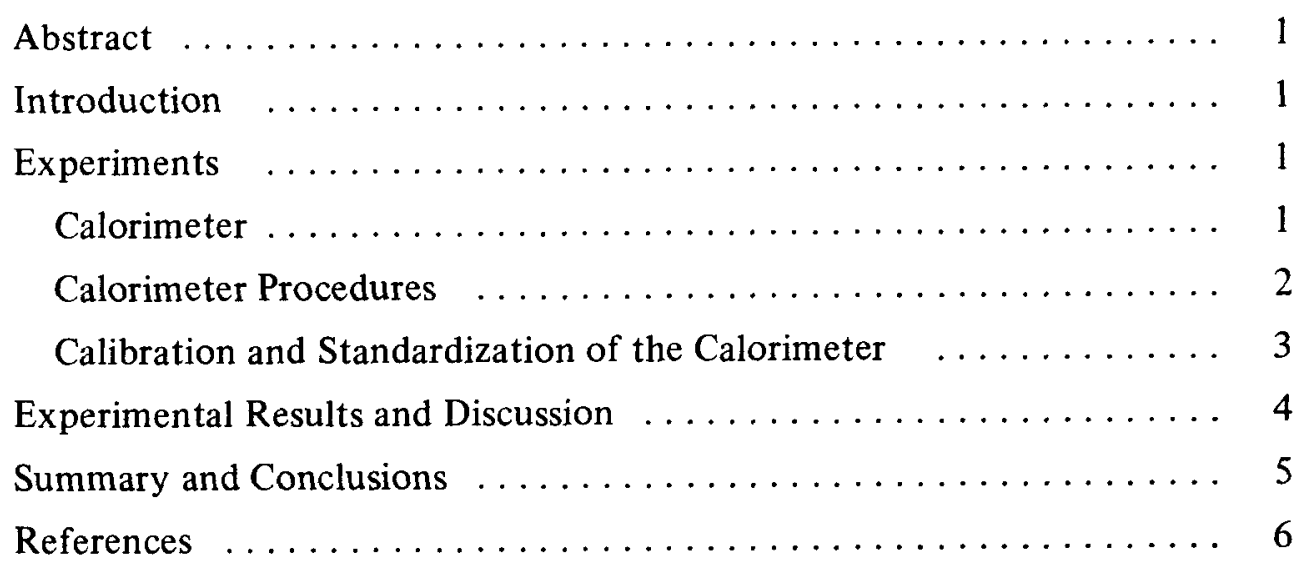


RFP-2170

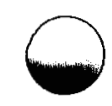




\section{ACKNOWLEDGMENTS}

The authors are indebted to the following individuals for their suggestions and assistance during the course of this work: D. K. Strangfeld and R. O. Adams for administrative duties, L. R. Crisler for the use of his apparatus, G. H. Bryan for his assistance in handling the material in the inert box, E. F. Lombardi for preparing hydride samples, and to H. L. Bramlet for analysis of the X-ray patterns. Without the cooperation of all these people, including Eunice Irwin for her secretarial assistance, this work could not have been completed in the allotted time span. 
RFP- 2170 


\title{
THE HEAT OF FORMATION OF PLUTONIUM HYDRIDE
}

\author{
Franklin L. Oetting and David R. Horrell
}

\begin{abstract}
The heat of formation of plutonium hydride with plutonium dihydride as the major constituent is $-45.6 \pm 3.6 \mathrm{kcal} / \mathrm{mole}$. The heat of formation of plutonium hydride having plutonium trihydride as the major constituent is $-48.0 \pm 3.7$ $\mathrm{kcal} / \mathrm{mole}$. These values were obtained by measuring heat associated with the following reactions:

$$
\begin{aligned}
& \mathrm{Pu}(\mathrm{c})+3 \mathrm{H}^{+} \rightarrow \mathrm{Pu}^{+3}(\mathrm{aq})+1 \frac{1}{2} \mathrm{H}_{2} \\
& \mathrm{Pu}^{+3}(\mathrm{aq})+2 \frac{1}{2} \mathrm{H}_{2} \rightarrow \mathrm{PuH}_{2}+3 \mathrm{H}^{+}
\end{aligned}
$$
\end{abstract}

or

$$
\mathrm{Pu}(\mathrm{c})+\mathrm{H}_{2} \rightarrow \mathrm{PuH}_{2}
$$

for the heat of formation of plutonium dihydride, and

$$
\begin{gathered}
\mathrm{Pu}(\mathrm{c})+3 \mathrm{H}^{+} \rightleftharpoons \mathrm{Pu}^{+3}(\mathrm{aq})+1 \frac{1}{2} \mathrm{H}_{2} \\
\mathrm{Pu}^{+3}(\mathrm{aq})+3 \mathrm{H}_{2} \rightleftharpoons \mathrm{PuH}_{3}+3 \mathrm{H}^{+}
\end{gathered}
$$

or

$$
\mathrm{Pu}(\mathrm{c})+1 \frac{1}{2} \mathrm{H}_{2} \rightleftharpoons \mathrm{PuH}_{3}
$$

for the heat of formation of plutonium trihydride.

\section{INTRODUCTION}

The first report on heat associated with the plutoniumhydrogen reaction was the work of Johns ${ }^{1}$ who, in 1947, reported the pressure-temperature relationship for the plutonium-hydrogen system. Johns reported $-32.5 \mathrm{kcal} / \mathrm{mole}$ for the heat of formation of plutonium dihydride at approximately $700^{\circ} \mathrm{K}$. Muford and Sturdy ${ }^{2}$ repeated Johns' vapor pressure work in 1954 at Los Alamos and reported -35.5 $\mathrm{kcal} / \mathrm{mole}$ for the heat of formation of plutonium dihydride at approximately $900^{\circ} \mathrm{K}$. In essence,
Muford and Sturdy confirmed the work of Johns. A later report ${ }^{3}$ corrected this vapor pressure data to $298^{\circ} \mathrm{K}$ and stated $-33.3 \pm 1.2 \mathrm{kcal} /$ mole as the heat of formation of plutonium dihydride at $298^{\circ} \mathrm{K}$ and $-33.0 \pm 3.0 \mathrm{kcal} / \mathrm{mole}$ for the heat of formation of plutonium trihydride.

More recent calorimetric investigations by Russian workers ${ }^{4}$ showed the heat of formation of plutonium trihydride as $-46.1 \pm 0.1 \mathrm{kcal} / \mathrm{mole}$. This differs substantially from American investigations. The Russian workers measured the heat of the reaction of hydrogen and plutonium directly in the calorimeter whereas the American values are based on vapor pressure measurements. Because of the significant difference in results $(-33$ vs. -46 $\mathrm{kcal} / \mathrm{mole}$ ), it seemed advisable to remeasure the heat of formation of plutonium hydride.

Our approach was somewhat different than either of the above investigations. We used a solution chemistry approach. This entailed the measurement of the heat of solution of plutonium metal in $6 \mathrm{~N} \mathrm{HCl}$ and the measurement of the heat of solution of plutonium hydride in $6 \mathrm{~N} \mathrm{HCl}$. The difference in these two heats was the heat of formation of plutonium hydride.

Our calorimetric system is by no means a precision calorimetric system, and it is emphatically recommended that the values reported here are not to be construed as precision calorimetric data. Our calorimetric results are of sufficient accuracy, however, to ascertain the value that should be used for the heat of formation of plutonium hydride.

\section{EXPERIMENTS}

\section{Calorimeter}

The calorimeter system (Figure 1) includes a dewar flask containing $200 \mathrm{ml}$ water. The reaction vessel, 


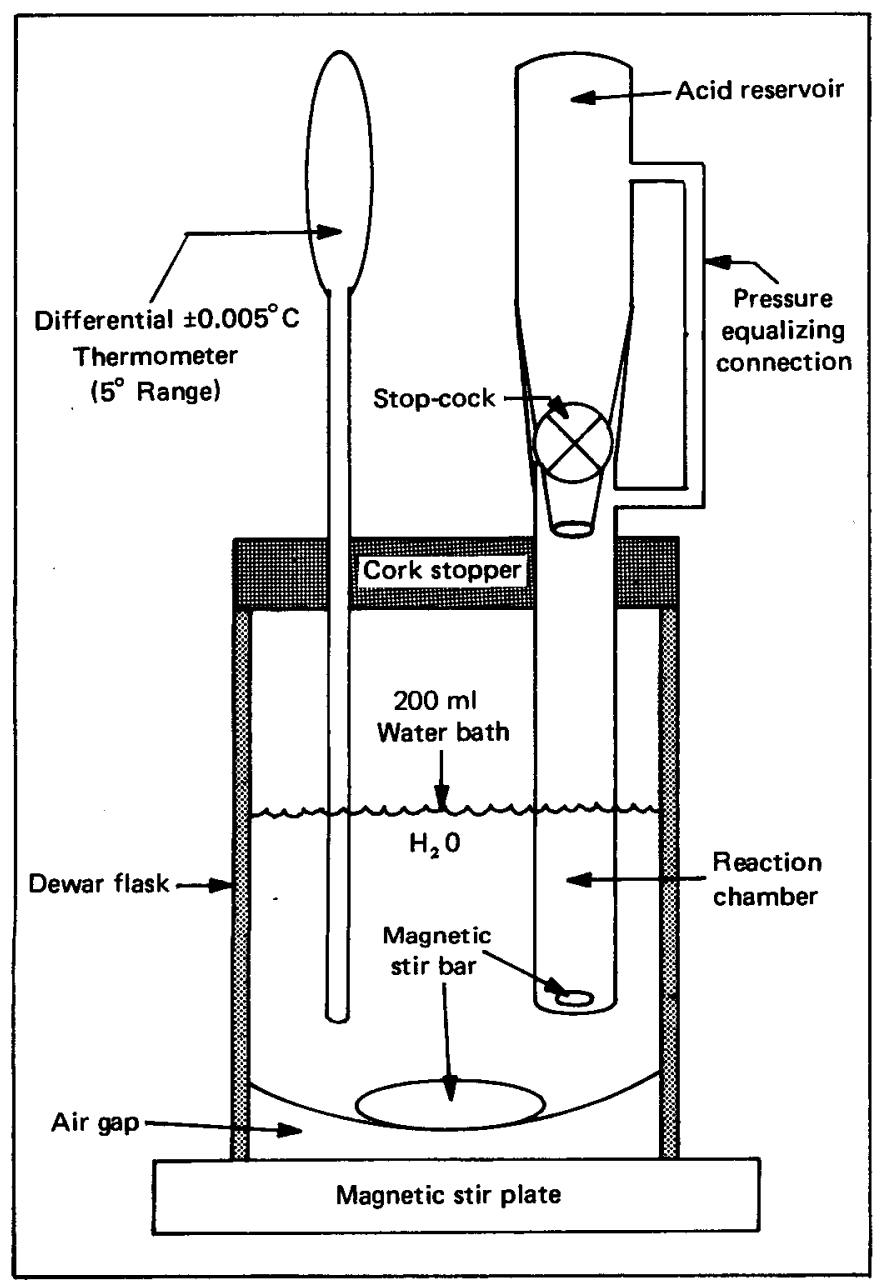

Figure 1. A Reaction Calorimeter.

which is submerged in the water, holds the metal or hydride as the case may be. The liquid reservoir, situated above the reaction vessel and connected by a stopcock, is outside the calorimeter proper. Initiation of the reaction between the acid in the reservoir and the metal in the reaction chamber is achieved by opening the stopcock and allowing the acid to flow onto the metal. The hydrogen evolved is allowed to escape through either the open stopcock or the pressure equalizing connection. In each experiment, there was a sufficiently violent reaction between the metal or hydride and the acid to achieve complete mixing; yet a magnetic stir bar was inserted in the reaction vessel to ensure complete mixing. Another magnetic stir bar was inserted in the $200 \mathrm{ml}$ of water to help transfer heat liberated from the reaction vessel to the calorimetric liquid. The temperature rise of the calorimeter was determined by a Beckman differential thermometer, which has a detection limit of 0.005 degree over a five-degree span.

\section{Calorimeter Procedures}

Although this calorimetric system may be described as being "rather crude" at best, most errors were at least partially eliminated by operating the calorimeter under exactly the same conditions in all experiments.

These conditions were as follows: It was determined initially that the differential thermometer read " 0 " at $20.0 \pm 0.01{ }^{\circ} \mathrm{C}$. Thus, the initial temperature of the calorimetric fluid was always monitored at $20^{\circ} \mathrm{C}$ or a few tenths of a degree above $20^{\circ} \mathrm{C}$. Before an experiment was initiated, the system temperature was observed over a 10minute period to determine the slope of the temperature rise during the initial period of an experiment. This slope was roughly $0.010^{\circ} \mathrm{C} / \mathrm{min}$ for all runs and was consistent for any given experiment. This temperature rise is caused by the heat evolved during mixing of the calorimetric liquid.

Two minutes before the reaction was to take place, the metal or hydride was inserted into the reaction chamber and exactly $10 \mathrm{ml}$ of acid was poured into the reservoir. The $10 \mathrm{ml}$ of acid had up to this time been in a large temperature bath at $20{ }^{\circ} \mathrm{C}$ so, in effect, the acid had the same initial temperature as the calorimeter liquid. The stopcock was then opened to initiate the reaction, and temperature rise versus time was recorded. The thermometer was read with the aid of a cathotometer glass and it was comparatively easy to read the thermometer to \pm 0.005 degree.

In all cases, the reaction was completed in 4 to 6 minutes. The final temperature-versus-time slope was then determined for a period of 10 minutes.

The temperature rise was determined by conventional means, i.e., by correcting the observed temperature rise for heating effects during the 
initial and final periods of the experiment. These effects were determined by observing the temperature rise for a period of time in the initial period before the reaction took place and in the final period following the reaction. The lines were then extrapolated to the mean time of the experiment, defined as 0.63 of the observed temperature rise. The corrected temperature rise was determined by plotting the entire temperature-time curve, extrapolating the initial and final period slope back to the mean time and then reading the initial and final temperature from the plot. The difference was the corrected temperature rise.

\section{Calibration and Standardization of the Calorimeter}

The calorimeter was standardized not by electrical means as is commonly the case but by the magnesium hydrochloric reaction, which is occasionally used as a standard in solution calorimetry. Standardization of any calorimeter implies determination of the energy equivalent, i.e., the amount of heat necessary to raise the calorimeter one degree centigrade. The magnesium-acid reaction was chosen primarily because it closely duplicates experimentally the plutonium and plutonium hydride-acid reaction; also, the heat of the magnesium-acid reaction is fairly well known.

The magnesium metal (Analytical Reagent Grade) was obtained from Mallinckrodt Chemical and contained approximately $0.2 \%$ impurities such as lead, iron, and manganese. Emission spectrographic results confirmed these impurities; however, the primary impurity to contend with is oxygen dissolved in the metal, which is difficult to accurately determine. Since this calorimeter is not a precision device, only metallic impurities were considered when calculating the heat evolved from dissolution of magnesium metal.

Shomate and Huffman ${ }^{5}$ initially determined the heat of solution of magnesium in $0.1 \mathrm{~N} \mathrm{HCl}$ and arrived at $-111.0 \mathrm{kcal} / \mathrm{mole}$. That took into account the heat process for vaporization of water carried off by evolving hydrogen. Correcting our metal for the heats of solution of the impurities and vaporization heat of water resulted in $4,558 \mathrm{cal}$ being evolved per gram of magnesium dissolution in $10 \mathrm{ml}$ of $0.1 \mathrm{~N} \mathrm{HCl}$. That was the value used to determine the energy equivalent of our calorimeter.

It is pertinent to point out that the magnesium experiments were conducted in exactly the same fashion as the plutonium and plutonium hydride experiments. In all cases, the proper amount of metal was used to give an approximate temperature rise of two degrees. Accordingly, approximately $0.1 \mathrm{~g}$ of magnesium was used to calibrate the calorimeter, i.e., establish the energy equivalent.

Five determinations on the magnesium-acid reaction, which determines the energy equivalent, were made with the following results: $216.9,221.5,220.4$, 220.1 , and $220.5 \mathrm{cal} /$ degree. This averages $219.9 \pm 1.7 \mathrm{cal} /$ degree for the energy equivalent of our calorimeter with the standard deviation being stated as the uncertainty.

In retrospect, $219.9 \mathrm{cal} /$ degree for the energy equivalent is realistic considering the calorimeter consists of $210 \mathrm{ml}$ of liquid and some glass in the reaction vessel and thermometer.

The calorimeter was checked by measuring the heat of solution of plutonium metal in $6 \mathrm{~N} \mathrm{HCl}$. The standard value for this reaction is between -138 and $-141 \mathrm{kcal} / \mathrm{mole}^{3}$ The variance in the data reported indicates this reaction should not be qualified as a standard reaction; however, it is similar to the investigation of delta stabilized plutonium ( 1 wt \% gallium) and acid.

Accordingly, six determinations were made on pure plutonium with the following results: -142.1 , $-142.9,-147.7,-141.6,-148.1$, and -138.9 $\mathrm{kcal} / \mathrm{mole}$. with the mean given as $-143.5 \pm 3.6$ $\mathrm{kcal} / \mathrm{mole}$ where the uncertainty is again the standard deviation from the mean. The molecular weight is taken as 239.05 grams/mole.

This result for the heat of solution of plutonium metal in $6 \mathrm{~N} \mathrm{HCl}$ is considered to be satisfactory for this calorimeter system, and indicates the work presented here can be in error by a few percent. There are refinements that could be made to this reaction if the primary objective was accurate thermochemical data. For example, no corrections 
were made for the impurities in the plutonium because this metal was comparatively pure $(99.8 \%)$. No attempt was made to vigorously exclude dissolved oxygen from the $\mathrm{HCl}$ solution since a very small portion of the plutonium ends up in the +4 state, because of oxygen, rather than the assumed +3 state. The heat effect due to the vaporization of water in the evolving hydrogen gas was insignificant. And finally, in accurate experimentation, there should be no oxygen in the atmosphere surrounding the metal.

These experiments partially fulfilled the obtaining of accurate thermochemical data; however, two minutes before reaction, the metal samples were exposed to a pseudo-inert atmosphere. For instance, when the sample was allowed to stand overnight in this box, a definite oxide coating was observed on unreacted metal.

The primary reason that these refinements were not applied to the measurements is that the calorimeter was not of sufficient accuracy to justify this additional treatment:

\section{EXPERIMENTAL RESULTS AND DISCUSSION}

The heat of formation of plutonium hydride, was determined by measuring the heat evolved in the following two reactions and subtracting $\Delta \mathrm{H}_{2}$ from $\Delta \mathrm{H}_{1}$.

$$
\begin{aligned}
& \mathrm{Pu}+3 \mathrm{H}^{+} \rightleftharpoons \mathrm{Pu}^{+3}+1.5 \mathrm{H}_{2} \Delta \mathrm{H}_{1} \\
& \mathrm{PuH}_{2}+3 \mathrm{H}^{+} \rightleftharpoons \mathrm{Pu}^{+3}+2.5 \mathrm{H}_{2} \Delta \mathrm{H}_{2}
\end{aligned}
$$

Since the primary objective of this report was to determine the heat evolved during the hydriding of delta plutonium, i.e., 1 wt \% gallium alloy, as opposed to pure plutonium, we have taken the liberty to denote $\mathrm{Pu}-1$ wt \% $\mathrm{Ga}$ as simply $\mathrm{Pu}$ or $\mathrm{PuH}_{2}$ in reactions (1) and (2).

Although reaction (1) is quite similar to the reaction of pure plutonium and $6 \mathrm{~N} \mathrm{HCl}$ as described in the previous section, the dissolution of $\mathrm{Pu}-1$ wt $\% \mathrm{Ga}$ in $6 \mathrm{~N} \mathrm{HCl}$ was measured in our calorimeter. The results of six determinations are as follows: $-139.3,-138.5,-140.2,-137.8,-141.1$, and $-142.7 \mathrm{kcal} / \mathrm{mole}$ where the mean is $-139.9 \pm 1.8$ $\mathrm{kcal} /$ mole. Again, the uncertainty is the standard deviation from the mean. The molecular weight is taken as 237.43 grams/mole.

Theoretically, the heat of solution value for delta plutonium should be like the value for alpha or pure plutonium. The main difference is the effect of gallium in the dissolution process. No attempt was made to correct the delta plutonium results for gallium, primarily because the correction would apply in both reactions (1) and (2), as the hydride was prepared from delta metal. In effect, heat for the gallium correction cancels out since gallium dissolves in acid in both cases. It is pertinent to mention that gallium does not form the hydride by direct hydrogenation as does plutonium. This conclusion is based on thermodynamic considerations.

The heat of dissolution of plutonium hydride in $6 \mathrm{~N} \mathrm{HCl}$ was measured using two different hydrides. The first hydride was prepared by reacting pure hydrogen and delta plutonium metal (the same metal that was used in the $\delta \mathrm{Pu}$ experiments) under a hydrogen pressure of 480 torr and allowed to stand for approximately one hour. During this time the hydrogen pressure decreased to 330 torr. $\mathrm{X}$-ray analysis on this material indicated the major constituent was $\mathrm{PuH}_{2}$ (hereafter referred to as $\mathrm{PuH}_{2}$ ).

The second hydride was prepared by reacting hydrogen under approximately seven atmospheres of pressure with delta plutonium (the same metal used in the $\delta \mathrm{Pu}$ experiments). As expected, X-ray indicated this hydride consisted primarily of $\mathrm{PuH}_{3}$ (hereafter referred to as $\mathrm{PuH}_{3}$ ). It is comparatively easy to distinguish between $\mathrm{PuH}_{2}$ and $\mathrm{PuH}_{3}$, by $\mathrm{X}$-ray analysis because of the cubic structure of $\mathrm{PuH}_{2}$ and the hexagonal structure of $\mathrm{PuH}_{3}$.

Results of five dissolution runs made on $\mathrm{PuH}_{2}$ in $6 \mathrm{~N} \mathrm{HCl}$ were: $-95.8,-98.4,-93.3,-90.0$, and $-94.1 \mathrm{kcal} / \mathrm{mole}$ with an average of $-94.3 \pm 3.1^{i}$ : $\mathrm{kcal} / \mathrm{mole}$ and the uncertainty being the standard deviation from the mean. The molecular weight was taken as 239.4 grams/mole. Accordingly, "if "." reactions (1) and (2) are rewritten as follows: 


$$
\begin{array}{r}
\delta \mathrm{Pu}(\mathrm{c})+3 \mathrm{H}^{+} \rightleftharpoons \delta \mathrm{Pu}^{+3}(\mathrm{aq})+1.5 \mathrm{H}_{2} \\
\Delta \mathrm{H}_{1}=-139.9 \pm 1.8 \mathrm{kcal} / \mathrm{mole}
\end{array}
$$

$$
\begin{aligned}
& \delta \mathrm{PuH}_{2}+3 \mathrm{H}^{+} \rightleftharpoons \delta \mathrm{Pu}^{+3}(\mathrm{aq})+2.5 \mathrm{H}_{2} \\
& \Delta \mathrm{H}_{2}=-94.3 \pm 3.1 \mathrm{kcal} / \mathrm{mole}
\end{aligned}
$$

then

$$
\begin{aligned}
\delta \mathrm{Pu}(\mathrm{c}) & +\mathrm{H}_{2} \rightleftharpoons \delta \mathrm{PuH}_{2}(\mathrm{c}) \\
\Delta \mathrm{H}_{3} & =\Delta \mathrm{H}_{1}-\Delta \mathrm{H}_{2}=-45.6 \pm 3.6 \mathrm{kcal} / \mathrm{mole}
\end{aligned}
$$

The difference (reaction 3 ) is the heat of formation of $\mathrm{PuH}_{2}$ (actually plutonium hydride whose major constituent is $\mathrm{PuH}_{2}$ ).

Similarly, six runs were made on $\mathrm{PuH}_{3}$ in $6 \mathrm{~N} \mathrm{HCl}$ with the following results: $-89.9,-89.0,-88.4$, $-96.1,-94.6$, and $\pm 93.4 \mathrm{kcal} / \mathrm{mole}$ with an average of $\pm 91.9 \pm 3.2 \mathrm{kcal} / \mathrm{mole}$ and the uncertainty being the standard deviation from the mean. The molecular weight is taken as 240.43 grams/mole. Accordingly, if reaction (1) is rewritten and reaction $(4)$ is written as follows:

$$
\begin{aligned}
\delta \mathrm{Pu}(\mathrm{c})+3 \mathrm{H}^{+} \rightleftharpoons & \delta \mathrm{Pu}^{+3}(\mathrm{aq})+1.5 \mathrm{H}_{2} \\
& \Delta \mathrm{H}_{2}=-139.9 \pm 1.8 \mathrm{kcal} / \mathrm{mole}
\end{aligned}
$$

$$
\begin{aligned}
& \delta \mathrm{PuH}_{3}+3 \mathrm{H}^{+} \rightleftharpoons \delta \mathrm{Pu}^{+3}(\mathrm{aq})+3 \mathrm{H}_{2} \\
& \Delta \mathrm{H}_{4}=-91.9 \pm 3.2 \mathrm{kcal} / \mathrm{mole}
\end{aligned}
$$

then

$$
\begin{aligned}
\delta \mathrm{Pu}(\mathrm{c}) & +1.5 \mathrm{H}_{2} \rightleftharpoons \mathrm{PuH}_{3}(\mathrm{c}) \\
\Delta \mathrm{H}_{5} & =\Delta \mathrm{H}_{1}-\Delta \mathrm{H}_{4}=-48.0 \pm 3.7 \mathrm{kcal} / \mathrm{mole}
\end{aligned}
$$

The difference (reaction 5) is the heat of formation of $\mathrm{PuH}_{3}$ (actually plutonium hydride whose major constituent is $\mathrm{PuH}_{3}$ ).

As in the case of plutonium metal, the plutonium hydrides were not corrected for impurities, primarily because the impurities, except for gallium, were insignificant. The vaporization of water was also insignificant. As mentioned previously, gallium does not form a hydride so, in effect, the heat of solution of gallium in acid is measured in both reactions and thus is cancelled out. As stated earlier, the one impurity that is difficult to contend with is oxygen, which was not included in the calculations.

Plutonium hydride, like alpha plutonium metal, is very reactive with oxygen as compared to delta plutonium metal. Even though we believed our experimental box contained a fairly inert atmosphere, it was not nearly as sophisticated as the box containing about $10 \mathrm{ppm} \mathrm{O}_{2}$ where such activities as sample preparations, weighings, and transfers were made. We surmised the spread in the mean of a given series of reactions would be larger when oxygen contamination was a significant factor. It must be realized, however, that in all cases our samples were not in contact with our pseudo-inert atmosphere for more than 2 minutes before the acid reaction was initiated.

\section{SUMMARY AND CONCLUSIONS}

A simple calorimetric system was devised to determine the heat of formation of plutonium hydride by solution calorimetry.

The calorimeter was calibrated with the known heat evolved from the reaction of magnesium and $0.1 \mathrm{~N} \mathrm{HCl}$ and checked by measuring the heat of solution of alpha plutonium metal in $6 \mathrm{~N} \mathrm{HCl}$. The results indicated a value of $-143.5 \pm 3.6$ $\mathrm{kcal} /$ mole compared to accepted values ranging from -138 to $-141 \mathrm{kcal} / \mathrm{mole}$. We consider the comparison acceptable for this type of calorimeter.

Two samples of plutonium hydride were prepared. One involved low pressure hydrogen and delta plutonium metal resulting in a sample having plutonium dihydride as its major constituent. The second sample used high pressure hydrogen and delta plutonium metal to get plutonium trihydride as the major constituent. These samples were dissolved in $6 \mathrm{~N} \mathrm{HCl}$ and the heats measured were $-94.3 \pm 3.1 \mathrm{kcal} / \mathrm{mole}$ for $\mathrm{PuH}_{2}$ and $-91.9 \pm 3.2$ $\mathrm{kcal} / \mathrm{mole}$ for $\mathrm{PuH}_{3}$. When these values were subtracted from the heat of solution of delta 
RFP-2170

plutonium in $6 \mathrm{~N} \mathrm{HCl}(-139.9 \pm 1.8 \mathrm{kcal} / \mathrm{mole})$ the resulting heats of formation were determined as follows:

$\mathrm{PuH}_{2}$ (major const.) $\Delta \mathrm{H}_{\mathrm{f}}=-45.6 \pm 3.6 \mathrm{kcal} / \mathrm{mole}$

$\mathrm{PuH}_{3}$ (major const.) $\Delta \mathrm{H}_{\mathrm{f}}=-48.0 \pm 3.7 \mathrm{kcal} / \mathrm{mole}$

Comparing the published values for the heat of formation of plutonium dihydride $(-33 \mathrm{kcal} / \mathrm{mole})$ and plutonium trihydride $(-46.1 \mathrm{kcal} / \mathrm{mole})$ with these results, it is suggested that the value of $-33 \mathrm{kcal} / \mathrm{mole}$ is in significant error and -46.1 $\mathrm{kcal} / \mathrm{mole}$ is near the true value.

\section{REFERENCES}

1. I. B. Johns, "Plutonium Hydride and Deuteride," MDDC-717, Argonne National Laboratory, Argonne, Illinois, (1947).

2. R. N. R. Mulford and G. E. Sturdy, J. Amer. Chem. Soc., 77, p 3449 (1955).

3. F. L. Oetting, Chem. Rev., 67, p 261 (1967).

4. M. I. Ivanov and N. S. Podol'skeya, Rus. J. of Phys. Chem., 45, p 1682 (1971).

5. C. H. Shomate and E. H. Huffman, J. Amer. Chem. Soc., 65, p 1625 (1943). 